\title{
Application of Social Network Analysis for Analyzing the Relationships between Root and Direct Causes of Defects
}

\author{
Chantelle Van Den Brink ${ }^{1} \&$ Sangwon Han $^{2}$ \\ ${ }^{1}$ School of Civil and Environmental Engineering, University of New South Wales, Sydney, Australia \\ ${ }^{2}$ Department of Architectural Engineering, University of Seoul, Seoul, Korea \\ Correspondence: Sangwon Han, Department of Architectural Engineering, University of Seoul, Seoul, Korea. \\ Tel: 82-2-6490-2764. E-mail: swhan@uos.ac.kr \\ Received: January 23, 2015 \\ Accepted: January 30, 2015 \\ Online Published: October 31, 2015 \\ doi:10.5539/mas.v9n12p12 \\ URL: http://dx.doi.org/10.5539/mas.v9n12p12
}

\begin{abstract}
This paper addresses the application of social network analysis (SNA) in understanding and representing the relationships between the root and direct causes of defects. The root and direct causes of construction defects were identified through extensive literature review, and the thoroughness of the identified causes was confirmed by examining 91 non-conformance reports. The SNA software UCINET was used to visually map the links between the direct and root causes for identifying the root causes that accounted for the majority of direct causes and defects. A measure of centrality and adjacency indicated that the root cause Constructor Error/Omission was directly linked to seven of the ten identified direct causes. It was also determined that eliminating this root cause together with Transportation Error would reduce the number of defects by $90 \%$. Since the root causes responsible for the majority of direct causes as well as the largest number of defects could be identified using SNA, it is concluded that SNA is a valuable tool for recognizing where resources should be employed for the elimination of defects.
\end{abstract}

Keywords: social network analysis, defects, causal relationships, quality management, non-conformance reports

\section{Introduction}

A defect is the physical manifestation of an error or omission (Mills et al., 2009), and rework is defined as the unnecessary effort required to redo a process or activity that was incorrectly implemented the first time (Love et al., 2009). The cost of defects and their resultant rework in a construction project can account for approximately $10 \%$ of the total project cost (Love \& $\mathrm{Li}, 2000$ ). In addition, rework can result in reduced profit, loss of market share and reputation, increased turnover of management and workforce, lower productivity, higher costs, and costly litigation between participants over the responsibility for overruns and delays (Love et al., 2009). Josephson et al. (2002) claimed that in order to improve the performance of projects, it is necessary to identify the causes and costs of construction rework so that they can subsequently be removed.

There have been numerous studies dedicated to identifying the causes and impact of defects. The impact of construction defects has been quantified by several researchers including Mills et al. (2009), Love and Smith (2003), Josephson et al. (2002), Barber et al. (2000), Love and Li (2000), Josephson and Hammarlund (1999), Willis and Willis (1996), and Burati et al. (1992). These research efforts confirmed that defects generally contribute a significant percentage of the total project cost while the specific amount varies with the type and size of the project. Love and Smith (2003) analyzed 161 construction projects in Australia and concluded that the cost of defects can be $12 \%$ of the total cost. Barber et al. (2000) reported that the cost of defects can be as high as almost $20 \%$ of the total project cost, which highlights the necessity of identifying and eliminating the causes of these defects in order to improve the performance of construction projects.

Several studies focused on identifying the various causes of defects including Hwang et al. (2009), Love et al. (2009), Busby and Hughes (2004), Love and Smith (2003), Josephson et al. (2002), Barber et al. (2000), Love and Li (2000), Josephson and Hammarlund (1999), Willis and Willis (1996), and Burati et al. (1992). Hwang et al. (2009) reported that the sources of rework include owner change, design error/omission, design change, vendor error/omission, vendor change, constructor error/omission, constructor change, transportation error, and other sources. According to Love and Smith (2003), rework resulted from changes requested by clients; changes 
initiated by clients; lack of experience and knowledge of design/construction process; ineffective use of information technologies; poor planning and coordination of resources; and inadequate managerial and supervisory skills. Barber et al. (2000) claimed that design errors account for about $50 \%$ of the total defect cost, while Love and $\mathrm{Li}(2000)$ reported that design changes and construction changes account for $32 \%$ and $23 \%$, respectively, of the total rework cost.

While numerous studies attempted to quantify the impact of defects and identify their causes, few studies endeavored to understand the causal relationship of construction defects. A defect is usually not the outcome of a single cause; rather, it occurs when several interrelated causes combine (Love et al., 2009). Therefore, construction managers can develop effective defect prevention strategies only after tracing the sequence of events and mechanics by analyzing these causal relationships (Aljassmi \& Han, 2014). Thus, it is important to analyze the complex causal relationships of construction defects in order to prevent their occurrence and the resultant rework. This paper suggests social network analysis (SNA) as a tool to better understand and visually analyze the interrelationships among the causes of defects.

\section{Causes of Construction Defects}

\subsection{Swiss Cheese Model}

In order to better understand the causal relationships of construction defects, it is important to thoroughly and systematically identify the causes of defects. For this purpose, the Swiss cheese model (Reason, 1959) was adopted. As shown in Figure 1, the Swiss cheese model consists of four layers, each of which represents a barrier to defects (i.e., Organizational Influences, Defective Supervision, Preconditions for Defective Acts, and Defective Acts); the holes in the first three layers represent the root causes, and those in the last layer represent the direct causes of a defect (Aljassmi \& Han, 2014). Root causes are defined as the most basic reasons for an undesirable condition, while direct causes are those that can primarily be attributed to individuals (Josephson \& Hammarlund, 1999).

The holes in each layer represent the variables that weaken each layer of defense and thereby increase the possibility of a defect (Aljassmi \& Han, 2014). These variables constitute the various causes of defects, ranging from the fundamental root causes to the most obvious, direct causes of defects. The size of the hole depends on the significance of the variable; that is, the size of the hole is relative to the contribution of the variable towards the formation of a defect. When the holes in the different layers align, a defect penetrates the defense layers and comes to light (Aljassmi \& Han, 2014). The paths these defects take to eventually come into existence are represented by the black lines in Figure 1 .

The Swiss cheese model has been used as the framework in this study for comprehensively and systematically identifying and classifying the root and direct causes of defects. This is because the paths that the defects take in this model provide a direct representation of what the relationships between direct and root causes of defects could look like.

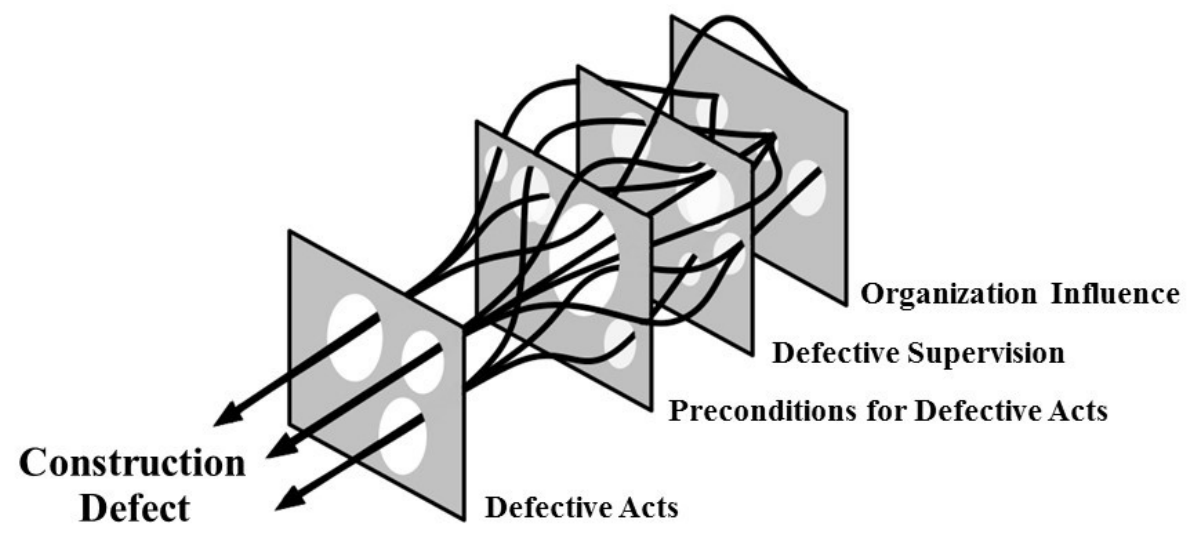

Figure 1. Swiss Cheese Model (modified from Aljassmi and Han (2014)

\subsection{Classification of Defect Causes}

After carefully reviewing the previous literature, the authors simplified the Swiss cheese model for the purposes of this paper. This paper considers the first three layers of the Swiss cheese model (Organizational Influences, 
Defective Supervision, and Preconditions for Defective Acts) to be parallel in terms of their impact on the final (direct cause) barrier, instead of dealing with the three layers separately. This is primarily due to the extent of the information available in the extant literature and the defect data used in this paper (discussed later in this section). For the classification of the root and direct causes, the authors adopted Josephson and Hammarlund's (1999) definitions of root causes (the most basic reasons for an undesirable condition) and direct causes of defects (those that can primarily be attributed to individuals).

The authors identified the eight variables for the root cause layer based on the classification suggested by Hwang et al. (2009), which was developed through the analysis of 359 construction projects. The eight variables include (1) owner change; (2) design error/omission; (3) design change; (4) constructor error/omission; (5) constructor change; (6) vendor error/omission; (7) vendor change; and (8) transportation error.

In addition, the authors identified nine variables for the direct cause layer based on Aljassmi and Han's (2014) classification system. This is because the nine defective acts described in their study can be directly related to the weaknesses present in the direct cause defense layer of the Swiss cheese model. The nine variables include (1) poor workmanship; (2) impaired materials usage; (3) task sequence omission; (4) deviation from intended dimension; (5) instruction contravention; (6) professional principles/conventions non-compliance; (7) official rule non-compliance; (8) items interdependence disregard; and (9) adoption of misguiding instruction.

After selecting and defining each cause variable, 91 non-conformance reports acquired from an Australian project management/engineering firm were analyzed to assess the completeness of the identified root and direct causes; each defect was classified according to one of the defined cause variables. The non-conformance reports were written by project and construction managers with at least ten years of experience in the industry. Of the 91 reports considered, 49 specified that either major rework or repairs were necessary as a result of physical defects and thus these 49 reports were finally chosen as the data set for analyzing the causes of construction defects.

Through the analysis of the non-conformance reports, one variable was additionally extracted, allowing for a set of variables that comprehensively described the causes of the sampled defects. The root cause layer (Hwang et al., 2009) was altered to include subcontractors in the Constructor Error/Omission and Constructor Change categories. Additionally, the direct cause layer (Aljassmi \& Han, 2014) was changed to include the variable Poor Handling, defined as "poor handling of materials that result in damage." The decision to include this variable was made during the process of classifying the data, when some of the direct causes could not be appropriately categorized using any of the variables presented by Aljassmi and Han (2014). Accordingly, the final set of categories for the root and direct causes of construction defects is shown in Table 1.

Table 1. Root and Direct Causes of Construction Defects

\begin{tabular}{|c|c|c|c|c|}
\hline Type & ID & Cause of Defect & Description & References \\
\hline \multirow{8}{*}{$\begin{array}{c}\text { Root } \\
\text { Causes }\end{array}$} & A1 & Owner Change & $\begin{array}{l}\text { Results caused by the owner changing the project } \\
\text { definition, scope, or requirements }\end{array}$ & $\begin{array}{l}\text { Hwang et al. } \\
(2009)\end{array}$ \\
\hline & $\mathrm{A} 2$ & $\begin{array}{l}\text { Design } \\
\text { Error/Omission }\end{array}$ & $\begin{array}{l}\text { Results caused when necessary items or components in } \\
\text { the project design are erroneous or omitted }\end{array}$ & $\begin{array}{l}\text { Hwang et al. } \\
\text { (2009) }\end{array}$ \\
\hline & A3 & Design Change & $\begin{array}{l}\text { Results caused when changes are made in the project } \\
\text { design or requirements }\end{array}$ & $\begin{array}{l}\text { Hwang et al. } \\
\text { (2009) }\end{array}$ \\
\hline & A4 & $\begin{array}{l}\text { Constructor } \\
\text { Error/Omission }\end{array}$ & $\begin{array}{l}\text { Results caused by contractors' error or omissions in } \\
\text { construction methods, procedures, activities, or tasks }\end{array}$ & $\begin{array}{l}\text { Hwang et al. } \\
\text { (2009) }\end{array}$ \\
\hline & A5 & $\begin{array}{l}\text { Constructor } \\
\text { Change }\end{array}$ & $\begin{array}{l}\text { Results caused by changing the constructors' } \\
\text { construction methods or procedures }\end{array}$ & $\begin{array}{l}\text { Hwang et al. } \\
\text { (2009) }\end{array}$ \\
\hline & A6 & $\begin{array}{l}\text { Vendor } \\
\text { Error/Omission }\end{array}$ & $\begin{array}{l}\text { Results caused when necessary items or components are } \\
\text { erroneous or omitted by vendors }\end{array}$ & $\begin{array}{l}\text { Hwang et al. } \\
(2009)\end{array}$ \\
\hline & A7 & Vendor Change & Results caused when vendors are changed & $\begin{array}{l}\text { Hwang et al. } \\
\text { (2009) }\end{array}$ \\
\hline & A8 & $\begin{array}{l}\text { Transportation } \\
\text { Error }\end{array}$ & $\begin{array}{l}\text { Results caused by mistakes, accidents, and errors in } \\
\text { transportation }\end{array}$ & $\begin{array}{l}\text { Hwang et al. } \\
(2009)\end{array}$ \\
\hline Direct & B1 & $\begin{array}{l}\text { Poor } \\
\text { Workmanship }\end{array}$ & $\begin{array}{l}\text { Constructing with a degree of skill that is considered } \\
\text { poor by the stakeholders }\end{array}$ & $\begin{array}{l}\text { Aljassmi and } \\
\text { Han (2014) }\end{array}$ \\
\hline Causes & $\mathrm{B} 2$ & Poor Handling & Poor handling of materials that result in damage & $\begin{array}{l}\text { Authors' } \\
\text { Refinement }\end{array}$ \\
\hline
\end{tabular}


B3 Impaired Materials Usage

B4 Task Sequence Omission

B5 Deviation from Intended Dimension

B6 Instruction Contravention

B7 Professional Principles/ Conventions Non-Compliance

B8 Official Rule Non-Compliance

B9 Items Interdependence Disregard

B10 Adoption Misguiding Instruction
Using or retaining the use of a material that is by any means not suitable for the constructed element Omitting a primary or a supplementary step in a task that is required to accomplish the job appropriately

Failing to comply with the exactly right dimension due to inaccuracy

Disregarding a detail or recommendation that is clearly provided by an instructor

Performing the job in a manner that is not in keeping with professionally established practices

Adopting work practices that do not comply with the state's rules and regulations

Performing a task in a manner that negatively affects another interrelated task

of Performing the job on the basis of a misleading instruction
Aljassmi and Han (2014)

Aljassmi and

Han (2014)

Aljassmi and

Han (2014)

Aljassmi and

Han (2014)

Aljassmi and

Han (2014)

Aljassmi and Han (2014)

Aljassmi and Han (2014)

Aljassmi and Han (2014)

\section{Application of Social Network Analysis}

\subsection{Social Network Analysis}

This paper adopts a social network analysis (SNA) approach to map the relationships between the causes of construction defects that were identified in the previous section. A social network is defined as a network consisting of a finite set of actors and the relation or relations defined on them (Fryke, 2004). For the purpose of this paper, the actors are considered to be the root and direct causes, and the paths between them represent the relations. Prior studies adopted SNA as a method for understanding the complex relationships among a number of different variables in the construction industry (Pryke, 2004; Pryke, 2005; Brookes et al., 2006; Chinowsky et al., 2008; Chinowsky et al., 2011; Ruan et al., 2012). SNA extends and complements traditional social science approaches by focusing on the causes and consequences of relations among various units (Ruan et al., 2012). The benefits of using SNA lie in the visualization of the relationships between variables through a sociogram. An example of a sociogram is provided in Figure 2; the letters A to E represent variables, and the lines connecting them represent the relations between them (Scott, 1988).

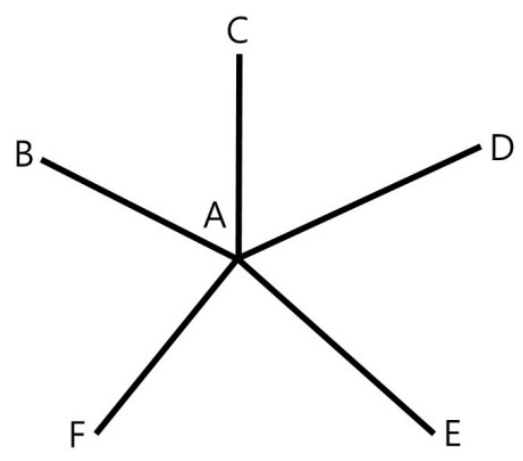

Figure 2. An Example of Sociogram

Scott (1988) details a number of parameters that are useful for visually interpreting these networks. These include the following:

- Adjacency: the number of other variables to which one variable is adjacent

- Centrality: variables that have the maximum number of adjacencies 
- Density: the ratio of the actual number of relations in the sociogram to the number that would be present if all the variables were linked to one another

- Clusters: a relatively densely connected clump of variables within a larger, less dense graph

\subsection{Data Conversion}

The software UCINET (Borgatti et al., 2002) was chosen to analyze the applicability and effectiveness of SNA in mapping the relations between the root and direct causes of defects. The first step in analyzing the applicability and effectiveness of SNA in this context was to convert the classified data (i.e., the causes) into a dataset that the UCINET software could interpret accurately. Subsequently, the dataset was processed to develop a network of relationships.

Conventional social science data consists of a rectangular array of measurements, where the rows represent different cases, and the columns consist of either quantitative or qualitative scores for the variables (Hanneman and Riddle 2005). In this case, the rows are taken to be the root causes of defects, while the columns represent the direct causes of defects. Therefore, each cell of this array would detail the number of ties or relations between the root and direct causes of defects. This data structure is effective and efficient for identifying any significant links between the root and direct causes.

The next stage involved the conversion of this 'conventional' data into 'network' data. The major difference between conventional and network data is that the former focuses on actors and attributes, while the latter focuses on actors and relations (Hanneman \& Riddle, 2005). Network analysis does not usually take into account the strength of the relational ties between root and direct causes; rather, it focuses on the number of relations that exist between root and direct causes.

The data that was in the matrix form was converted into a Data Language (DL) file. A typical DL file consists of a set of numbers preceded by a series of keywords and phrases that describe the data (Borgatti et al., 2002). Among the various DL file types available, Linked List formats can accept character data, and therefore, can handle two-mode data, i.e., data with two sets of variables (Borgatti \& Everett, 1997). The dataset in this paper is of this type - the root causes of defects represent one set of variables, and the direct causes represent another. Of the two Linked List formats available (Nodelist \& Edgelist), the Edgelist data type was adopted because it allows the analysis of matrices with valued data as opposed to matrices consisting of only binary data (Borgatti et al., 2002). Table 2 shows the two-mode data matrix used in this paper. Each row represents root cause and each column represents direct cause. The numbers in the matrix represent the number of occurrence of a construction defect generated by a specific pair of a root cause and a direct cause. For example, 16 defects were generated by A4 (Constructor Error/Omission) and B1 (Poor Workmanship).

Table 2. Two-mode Data Matrix

\begin{tabular}{ccccccccccc}
\hline & B1 & B2 & B3 & B4 & B5 & B6 & B7 & B8 & B9 & B10 \\
\hline A1 & 0 & 0 & 0 & 0 & 0 & 0 & 0 & 0 & 0 & 0 \\
A2 & 0 & 0 & 0 & 0 & 0 & 0 & 0 & 0 & 0 & 1 \\
A3 & 0 & 0 & 0 & 0 & 0 & 0 & 0 & 0 & 0 & 1 \\
A4 & 16 & 0 & 0 & 2 & 5 & 5 & 3 & 2 & 1 & 0 \\
A5 & 0 & 0 & 0 & 0 & 0 & 0 & 0 & 0 & 0 & 0 \\
A6 & 1 & 0 & 0 & 0 & 0 & 1 & 0 & 0 & 0 & 1 \\
A7 & 0 & 0 & 0 & 0 & 0 & 0 & 0 & 0 & 0 & 0 \\
A8 & 0 & 10 & 0 & 0 & 0 & 0 & 0 & 0 & 0 & 0 \\
\hline
\end{tabular}

\subsection{Visualization and Analysis of the Network}

Once the conventional data in the matrix form was converted to the Edgelist text file format, it was imported into UCINET for analysis. Once the network was developed, it was visually analyzed using the tools provided in the software. The analysis particularly looked for variables with a high degree of centrality (variables that had a high number of connections to other variables) and for the presence of clusters (the denser areas in the network) in order to draw some conclusions about the most fundamental root causes of defects. 
It was necessary to create a sociogram to depict the relations between the root and direct causes of defects. The data file created in the previous section was opened in NetDraw (UCINET's visualization tool), and the sociogram was produced as shown in Figures 3(a) and (b). The red dots in Figure 3 represent the root causes of defects, and the blue squares represent the direct causes of defects. Figure 3(a) shows that there is one major cluster in this network around the root cause Constructor Error/Omission (A4); therefore, this root cause is the reason for most concern. This root cause has the highest degree of adjacency (i.e., the number of other variables to which one variable is adjacent), as it is directly linked to seven out of the ten direct causes listed. That is, Constructor Error/Omission (A4) has seven adjacent nodes (B1, B4, B5, B6, B7, B8, and B9). It can also be described as the most central point in this network. If this root cause were to be removed, it would subsequently result in the elimination of five of the direct causes of defects (B4, B5, B7, B8, and B9). The second most central root cause is Vendor Error/Omission (A6). If this root cause were to be removed next, another two of the direct causes listed would cease to exist (B1 and B6). It can also be seen that the root causes Owner Change (A1), Constructor Change (A5), and Vendor Change (A7), together with the direct cause Impaired Materials Usage (B3) did not result in the formation of defects for this particular project.

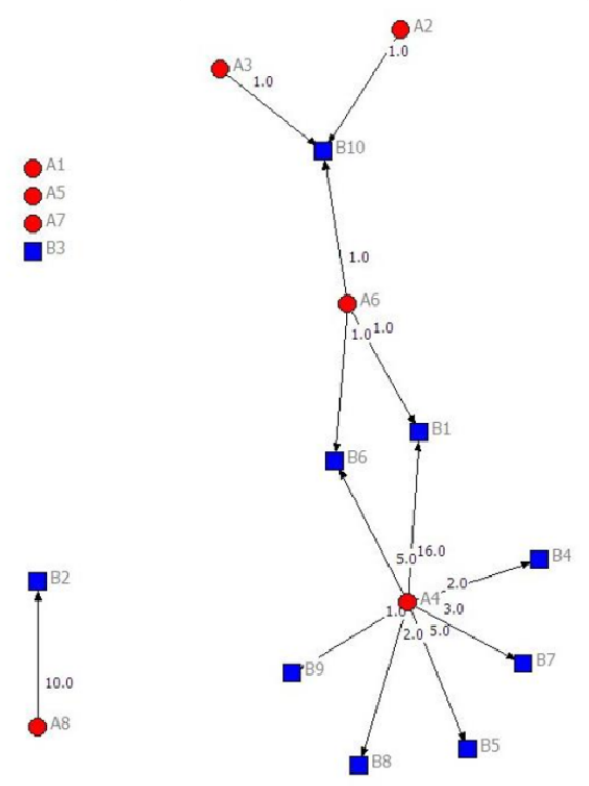

(a) Link Weighting

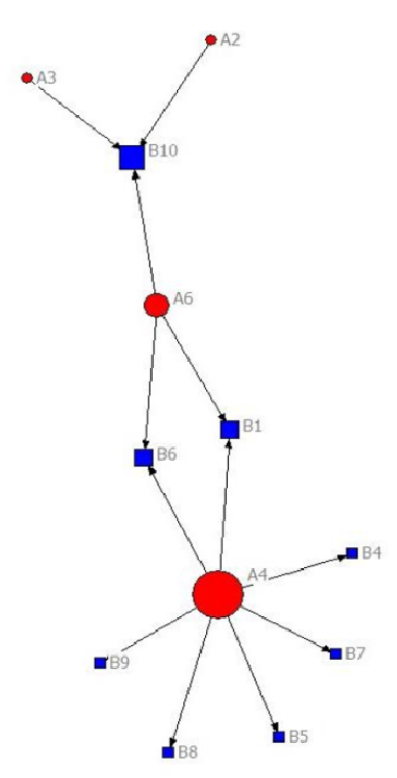

(b) Degree Centrality

Figure 3. Sociogram with Link Weighting and Degree Centrality

Another issue to note from this interpretation is that the strength of each relation (i.e., line connecting a root and a direct cause) is different. To address this, the weighting of each relation in the sociogram is displayed with the number of defect occurrences in each relation as shown in Figure 3(a). While Transportation Error (A8) has a relation with Poor Handling (B2) only, this root cause accounts for ten of the 49 defects identified by analyzing the non-conformance reports, and it is the second strongest link in the entire network (see Table 2 and Figure 3(a)). The strongest link lies between the root cause Constructor Error/Omission (A4) and the direct cause Poor Workmanship (B1), as it accounts for 16 of the 49 defects reported. Therefore, elimination of only two of the eight root causes (Constructor Error/Omission (A4) and Transportation Error (A8)) is expected to prevent 44 (16 $+2+5+5+3+2+1+10$ ) of the 49 defects (i.e., $90 \%$ of the total number of defects) recorded in the non-conformance reports analyzed in this paper as below.

- 16 defects caused by $\mathrm{A4}$ and B1

- 2 defects caused by A4 and B4

- $\mathbf{5}$ defects caused by $\mathbf{A} 4$ and B5

- $\mathbf{5}$ defects caused by A4 and B6 
- 3 defects caused by A4 and B7

- 2 defects caused by A4 and B8

- 1 defect caused by A4 and B9

- $\mathbf{1 0}$ defects caused by A8 and B2

As previously discussed, the network density is defined as the ratio of the actual number of relations in the sociogram to the number that would be present if all the variables were linked to one another. In this network, 13 relations are found among root and direct causes and the maximum possible number of relations are 80 ( 8 root and 10 direct causes). Thus, the network density in Figure 3(a) is 0.1625 (i.e., 13/80). As such, since the network density is relatively low, it is easy to visually distinguish areas of concern. However, if the network had been much denser, it might have been difficult to visually identify the areas of the network that are most significant. Thus, it would be effective to measure the degree of centrality of each node and depict the size of each node in a sociogram. Figure 3(b) illustrates the degree of centrality of each root cause and direct cause assigned to and depicted in the size of the nodes. As was mentioned before, the root cause Constructor Error/Omission (A4) is the reason for most concern; it is now represented by the largest red dot in the sociogram (Figure 3(b)). Although it is not necessary to distinguish the most significant causes in this low density network, depicting the degree of centrality in the form of node size could potentially be a very useful tool in denser networks. While one main benefit of using SNA is to visualize the relationships between the root and direct causes of defects, if the network is very complicated, it would be difficult to visually analyze the network. Thus, it would be useful to quantitatively measure the degrees of adjacency, centrality, and density together, and then identify the clusters quantitatively.

Figure 4 shows the quantitative measurement of the degrees of centrality of each node. For example, the highest degree of centrality is found to be in the root cause Constructor Error/Omission (A4). The degree of centrality is calculated as 0.700 (i.e., A4 has seven links out of ten possible links). This output is consistent with what was observed in the visual network in the previous section, where Constructor Error/Omission was linked to seven of the ten direct causes of defects.

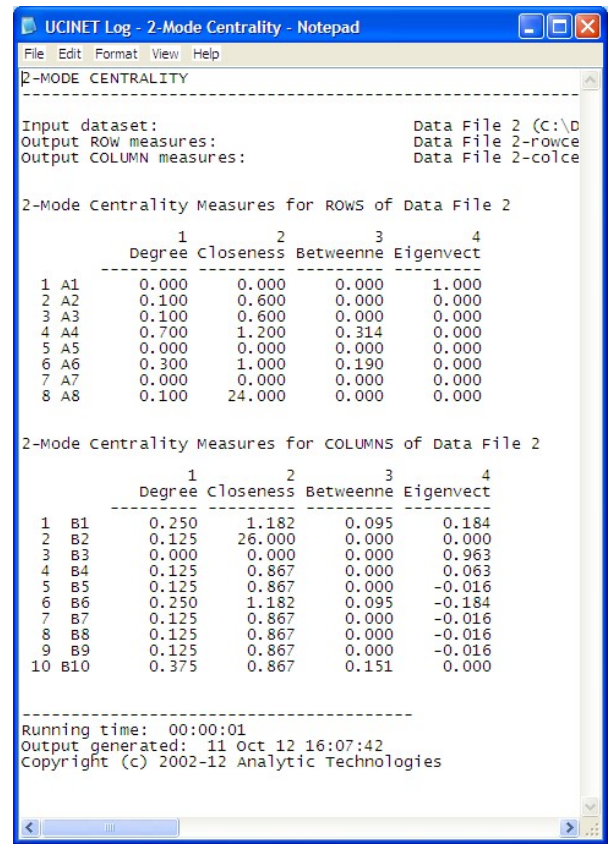

Figure 4. Two-mode Centrality Output

\section{Conclusions}

This paper aimed to assess the applicability and effectiveness of SNA for providing a better understanding and representation of the relationship between the root and direct causes of construction defects. The ultimate goal was to identify the causes that accounted for the majority of the defects, so that attention could be paid to their removal in future projects, thereby reducing the cost of repairs and rework in construction.

The SNA software UCINET was used to visually map the relationships between the root and direct causes of 
defects. The visual analysis of this network identified Constructor Error/Omission as the most significant root cause, as it was directly linked to seven of the ten direct causes, and therefore had the highest level of adjacency and centrality when compared to the other root causes.

An analysis of the strength of the relationships between the root causes and direct causes of defects also proved valuable when used in conjunction with SNA. This analysis identified the root causes that accounted for the largest number of defects, as well as those that accounted for the largest number of direct causes. For the defect data recorded in the non-conformance reports analyzed in this paper, it was shown that removing two of the eight root causes (Constructor Error/Omission and Transportation Error) would have prevented $90 \%$ of the defects analyzed.

The successful application of UCINET in visually mapping and analyzing the relationships between the root and direct causes of construction defects indicates that SNA has a great potential in providing a better understanding and representation of the relationships between these causes. Also, the finding that the root causes responsible for both the majority of direct causes as well as the largest number of defects could be identified using SNA supports that it is a valuable tool for recognizing where resources should be allocated for effective elimination of construction defects.

While this paper strides a meaning step to analyze the relations between root and direct causes of construction defects through application of social network analysis, this paper is limited in considering only the direct path that a defect might take from its root cause to its direct cause. Thus, further research needs to extend this analysis to include all the four barriers to defects represented in the Swiss cheese model. For this, a deep understanding of the causes of defects and systematic classification of non-conformance reports is required. Further, the efficient recording of such information at the time of the defect occurrence is imperative for producing accurate results.

\section{Acknowledgments}

This research was supported by Basic Science Research Program through the National Research Foundation of Korea(NRF) funded by the Ministry of Science, ICT and Future Planning(2013010660).

\section{References}

Aljassmi, H., \& Han, S. (2014). Classification and Occurrence of Defective Acts in Residential Construction Projects. Journal of Civil Engineering and Management, 20(2), 175-185. http://dx.doi.org/10.3846/13923730.2013.801885

Barber, P., Graves, A., Hall M., Sheath, D., \& Tomkins C. (2000). Quality failure costs in civil engineering projects. International Journal of Quality \& Reliability Management, 17(4), 479-492. http://dx.doi.org/10.1108/02656710010298544

Borgatti, S. P., \& Everett, M. G., (1997). Network Analysis of 2-Mode Data. Social Networks, 19(3), 243-269. http://dx.doi.org/10.1016/S0378-8733(96)00301-2

Borgatti, S. P., Everett, M. G., \& Freeman, L. C. (2002a). UCINET 6 for Windows: Software for Social Network Analysis User's Guide. Harvard, MA: Analytic Technologies.

Borgatti, S. P., Everett, M. G., \& Freeman, L. C. (2002b). UCINET for Windows: Software for Social Network Analysis. Harvard, MA: Analytic Technologies.

Brookes, N. J, Morton, S. C., Dainty, A. R. J., \& Burns, N. D. (2006). Social Processes, Patterns and Practices and Project Management: A Theoretical Framework and an Empirical Investigation. International Journal of Project Management, 24(6), 474-482. http://dx.doi.org/10.1016/j.ijproman.2006.03.005

Burati, J. S., Farrington, J. J., \& Ledbetter, W. B. (1992). Causes of Quality Deviations in Design and Construction. Journal of Construction Engineering Management, 118(1), 34-49. http://dx.doi.org/10.1061/(ASCE)0733-9364(1992)118:1(34)

Busby, J. S., \& Hughes, E. J. (2004). Projects, Pathogens and Incubation Periods. International Journal of Project Management, 22(5), 425-434. http://dx.doi.org/10.1016/j.jproman.2003.09.002

Chan, D. W. M., \& Kumaraswamy, M. M. (1997) A Comparative Study of the Causes of Time and Cost Overruns in Hong Kong Construction Projects. International Journal of Project Management, 15(1), 55-63. http://dx.doi.org/10.1016/S0263-7863(96)00039-7

Fernandez-Sanchez, G., \& Rodriguez-Lopez, F. (2010). A Methodology to Identify Sustainability Indicators in Construction Project Management - Application to Infrastructure Projects in Spain. Ecological Indicators, 10(6), 1193-1201. http://dx.doi.org/10.1016/j.ecolind.2010.04.009 
Hanneman, R. A., \& Riddle, M. (2005). Introduction to Social Network Methods, University of California, Riverside, CA (published in digital form at http://faculty.ucr.edu/ hanneman/).

Hwang, B. G., Thomas, S. R., Haas, C. T., \& Caldas, C. H. (2009). Measuring the Impact of Rework on Construction Cost Performance. Journal of Construction Engineering and Management, 135(3), 187-198. http://dx.doi.org/10.1061/(ASCE)0733-9364(2009)135:3(187)

Josephson, P. E, Larrson, B., \& Li, H. (2002). Illustrative Benchmarking Rework and Rework Costs in Swedish Construction Industry. Journal of Management in Engineering, 18(2), 76-83. http://dx.doi.org/10.1061/(ASCE)0742-597X(2002)18:2(76)

Josephson, P. E., \& Hammarlund, Y. (1999). The Causes of Costs of Defects in Construction: A Study of Seven Building Projects. Automation in Construction, 8(6), 681-687. http://dx.doi.org/10.1016/S0926-5805(98)00114-9

Love, P. E. D., \& Li, H. (2000). Quantifying the Causes and Costs of Rework in Construction. Construction Management and Economics, 18(4), 479-490. http://dx.doi.org/10.1080/01446190050024897

Love, P. E. D., \& Smith, J. (2003). Benchmarking, Benchaction, and Benchlearning: Rework Mitigation in Projects. Journal of Management in Engineering, 19(4), 147-159. http://dx.doi.org/10.1061/(ASCE)0742-597X(2003)19:4(147)

Love, P. E. D., Edwards, D. J., Irani, Z., \& Walker, D. H. T. (2009). Project Pathogens: The Anatomy of Omission Errors in Construction and Resource Engineering Project. IEEE Transactions on Engineering Management, 56(3), 425-435. http://doi.org/10.1109/TEM.2008.927774

Mills, A., Love, E. D., \& Williams, P. (2009). Defect Costs in Residential Construction. Journal of Construction Engineering and Management, 135(1), 12-16. http://dx.doi.org/ 10.1061/(ASCE)0733-9364(2009)135:1(12)

Pryke, S. D. (2004). Analysing Construction Project Coalitions: Exploring the Application of Social Network $\begin{array}{lllll}\text { Analysis. Construction Management and Economics, 22(8), } & \text { 787-797. }\end{array}$ http://dx.doi.org/10.1080/0144619042000206533

Pryke, S. D. (2005). Towards a Social Network Theory of Project Governance. Construction Management and Economics, 23(9), 927-939. http://dx.doi.org/10.1080/01446190500184196

\section{Copyrights}

Copyright for this article is retained by the author(s), with first publication rights granted to the journal.

This is an open-access article distributed under the terms and conditions of the Creative Commons Attribution license (http://creativecommons.org/licenses/by/3.0/). 